\begin{tabular}{|c|c|c|c|}
\hline & GRI & VICH CLOC & \\
\hline & & $\begin{array}{c}\text { Mean } \\
\text { Daily Rate }\end{array}$ & $\begin{array}{c}\text { Mean } \\
\text { Deviation }\end{array}$ \\
\hline & 1905 & s. & s. \\
\hline Feb. & $1-4$ & -.243 & .016 \\
\hline & $6-12$ & .225 & .002 \\
\hline & $12-21$ & .225 & .002 \\
\hline & 21-March 1 & .258 & .031 \\
\hline March & $2-12$ & .228 & .001 \\
\hline & $12-18$ & .220 & .007 \\
\hline & $18-24$ & .200 & .027 \\
\hline & 24-Apr. 1 & .217 & .010 \\
\hline April & $1-8$ & .222 & .005 \\
\hline & $8-16$ & .222 & .005 \\
\hline & $16-23$ & .178 & .049 \\
\hline & 23-May 1 & .232 & .005 \\
\hline May & $1-6$ & .248 & .021 \\
\hline & $6-12$ & -.274 & .047 \\
\hline & Mean & -.227 & \pm .018 \\
\hline
\end{tabular}

Time Department,

Royal Observatory, Greenwich

\section{REASONS FOR BELIEVING IN AN ETHER}

Several weeks ago an article with this title appeared in ScIENCE. In it were mentioned two reasons for the belief in an ether; but what seems to me the most powerful of all arguments was not mentioned, nor is it often referred to elsewhere. It is alluded to by Maxwell in his article 'Ether," where we find these words:

In the next place, this energy is not transmitted instantaneously from the radiating body to the absorbing body, but exists for a time in the medium.

The ether was originally invented to avoid the assumption of action at a distance; but there are no insuperable objections to action at a distance provided it be instantaneous. Herein lies the point of the argument. We have replaced the old question: "Can a body act where it is not?" by the far more searching question: "Can a body act when it is not?"

The energy sent out by the sun, for instance, reaches the earth after a lapse of some eight minutes. What of the energy during

\footnotetext{
${ }^{1}$ Encyc. Brit., ninth edition, Vol. VIII., p. 570.
}

that time? The principle of the conservation of energy forbids our supposing that it is annihilated and recreated eight minutes later; and it will hardly be urged, I think, that it exists as a sort of disembodied spirit during that interval. There must be some medium in which it may reside during its finite time of passage from place to place.

The ether stands or falls with the principle of the conservation of energy.

\section{Paul R. Heyl}

\section{THE FIRST SPECIES RULE}

The article by Professor John B. Smith in the May 10 number of ScIENcE under the above title, in which exception is taken to the operation of the first species rule in the case of the lepidopterous genus Rhynchagrotis Smith, can hardly be considered as an argument against the use of this method of type fixing. His objection is against the selection of a doubtfully referred species as the type of a genus, a matter which is fully covered in most, if not all, codes and is entirely independent of the method of selecting types, whether by elimination or first species rule.

In the specific case mentioned by Professor Smith we fail to see that the species chardinyi selected as the type by Sir George Hampson was 'questionably referred,' as in the original description Professor Smith says: "The group, though placed with, and certainly very closely allied to cupida, yet shows so many peculiar characteristics that it would seem possible to separate it by a distinct generic term. The two species rufipectus and brunneicollis are, however, somewhat intermediate and as the species (chardinyi) can hardly be referred to Triphana, I prefer to leave it here." Regarding this Professor Smith states in his recent article: "my reason for placing it there being that $\mathrm{I}$ believed it would prove to be properly referable to an exotic genus to which I did not care to risk making a synonym."

$$
\begin{aligned}
& \text { Adademy of Natural Sciences, } \\
& \text { Philadelphia, Pa., } \\
& \text { May } 17,1907
\end{aligned}
$$

